\title{
Low-temperature heat capacity and thermodynamic functions of $\mathrm{IrO}_{2}{ }^{a}$
}

\author{
RAMON BURRIEL, ${ }^{h}$ EDGAR F. WESTRUM, JR., \\ Department of Chemistry, University of Michigan, Ann Arbor, \\ Michigan 48109 , U.S.A. \\ and E. H. P. CORDFUNKE \\ Netherlands Energy' Research Foundation ECN. \\ Petten (NH). The Netherlands
}

(Received 29 Octoher 1986; in final form 6 August 1987)

\begin{abstract}
The heal capacity from 5 to $350 \mathrm{~K}$ of $\mathrm{IrO}_{2}$ has been measured by quasi-adiabatic equilibrium calorimetry. The values for the thermodynamic properties at $298.15 \mathrm{~K}$ have been calculated as $C_{p, \mathrm{~m}}(T) / R=6.687, \Delta_{0}^{T} S_{\mathrm{m}}^{\lrcorner} / R=6.133, \Delta_{0}^{T} H_{\mathrm{m}}^{\lrcorner} /(R \cdot \mathrm{K})=1039.5$, and $\Phi_{\mathrm{m}}^{\circ}(T, 0) / R=2.647$. The lowtemperature heat capacity shows typical metallic behavior with an electronic coefficient $y / R=0.00067 \mathrm{~K}^{-1}$. The entropy at $298.15 \mathrm{~K}$ is shown to be consistent with the volumetric dependence of this quantity.
\end{abstract}

\section{Introduction}

Transition-metal dioxides with rutile and related structures display an interesting range of physical properties which correlate with the number of free d-electrons of the metal ions, ranging from insulators $\left(\mathrm{TiO}_{2}, \mathrm{~d}^{\mathrm{O}}\right)$ through semi-metallic and on to metallic conductors $\left(\mathrm{MoO}_{2}, \mathrm{TcO}_{2}, \mathrm{RuO}, \mathrm{RhO}_{2}, \mathrm{WO}_{2}, \mathrm{ReO}, \mathrm{OsO}_{2}, \mathrm{IrO}_{2}, \mathrm{PtO}_{2}\right)$ as well as providing the interesting metal-to-insulator transitions as for $\mathrm{VO}_{2}, \mathrm{NbO}_{2}$ and magnetic ordering $\left(\mathrm{MnO}_{2}, \mathrm{CrO}_{2}\right)$. Their stability and electrical properties make them important materials for technical applications as electrodes, film resistors. heating elements, crucibles, and catalysts.

The thermochemical properties of $\mathrm{IrO}_{2}$ have been extensively studied by means of electromotive force, oxygen dissociation pressure. high-temperature enthalpy increment, thermogravimetric, and d.t.a. measurements.

Calorimetric heat-capacity measurements available were only those below $10 \mathrm{~K}$ (by Passenheim and McCollum) ${ }^{(1)}$ and above $290 \mathrm{~K}$ (by Wöhler and Jochum).(2) These latter values have been often criticized as being unreliable. Only recently Cordfunke ${ }^{(3)}$ has re-measured the high-temperature enthalpy increments and

\footnotetext{
"Supported in part by the Structural Chemistry and Chemistry Thermodynamics Program of the Division of Chemistry, National Science Foundation under Grant CHE-8007977.

" Present address: Instituto de Ciencia de los Materiales de Aragón. Departamento de Termologia. lniversidad de Zaragoza, 50009-Zaragoza, Spain.
} 
re-evaluated experimental results in the literature with the new values calculated here, obtaining consistent results for third-law evaluations.

\section{Experimental}

The $\mathrm{IrO}_{2}$ was prepared by oxidation (in oxygen) of $\mathrm{IrCl}_{3}$ at $1273 \mathrm{~K}$ overnight. The $\mathrm{IrCl}_{3}$ was obtained as a green microcrystalline powder by chlorination of iridium powder at about $873 \mathrm{~K}$. The analysis of the iridium content of the $\mathrm{IrO}_{2}$ sample was 86.04 per cent by mass (calculated 85.73 ).

A $36.80 \mathrm{~g}$ sample was loaded into the gold-plated copper calorimeter (laboratory designation $\mathrm{W}-50$ ) provided with a screw-type closure with a stainless-steel knife edge and an annealed gold gasket. The loaded calorimeter was evacuated and $2.7 \mathrm{kPa}$ of helium gas was added at $300 \mathrm{~K}$ to facilitate thermal contact between sample and calorimeter.

Heat-capacity measurements were made in the range 5 to $350 \mathrm{~K}$ in the Mark II adiabatic cryostat. ${ }^{(4)}$ The calorimeter was surrounded by a shield system provided with automatic temperature control. A Leeds and Northrup capsule-type platinum resistance thermometer (laboratory designation A-5) was used for temperature determinations. The thermometer was calibrated at the U.S. National Bureau of Standards (N.B.S.) against IPTS-48 (as textually revised in 1960$)^{(5)}$ for temperatures above $90.2 \mathrm{~K}$, against the N.B.S. provisional scale from 10 to $90 \mathrm{~K}$. and by the calibration technique of $\mathrm{McCrackin}$ and $\mathrm{Chang}^{(6)}$ below $10 \mathrm{~K}$. These calibrations are judged to reproduce thermodynamic temperatures to within $0.03 \mathrm{~K}$ from 10 to $90 \mathrm{~K}$ and to within $0.04 \mathrm{~K}$ above $90 \mathrm{~K}$. Determinations of mass, current, potential difference, and time are referred to standardizations and calibrations performed at the N.B.S. The accuracy of a single heat-capacity measurement is considered to bc about 0.5 per cent from 10 to $15 \mathrm{~K}$ increasing to about 0.1 per cent between 30 and $350 \mathrm{~K}$.

\section{Results}

The heat-capacity of $\mathrm{IrO}_{2}$ is represented by a simple sigmate curve with contributions only from the free-electron gas and the lattice vibrations. The measured heat capacity of $\mathrm{IrO}_{2}$ is listed in chronological order in table 1 and represented graphically in figure 1 . The experimental heat capacities were processed by subtraction of the heat capacity of the empty calorimeter and corrected for the small differences in the amounts of helium gas and gold gasket relative to the calorimeter when measured empty. The calorimeter and (thermometer + heater) assembly represent 20 to 30 per cent of the total measured heat capacity except in the region of high $C_{p}$, where they decreased to 5 per cent. Curvature corrections were applied to obtain the heat capacity $\left\{C_{p}=(\partial H / \partial T)_{p}\right\}$ from the measured $\Delta H / \Delta T$ values. The approximate temperature increments employed usually can be estimated from the adjacent mean temperature in table 1 . The results were fitted to a power series in orthogonal polynomials as described by Justice. ${ }^{(9)}$ Below $5 \mathrm{~K}$. heat-capacity values were extrapolated by fitting the measured values below $65 \mathrm{~K}$ to a polynomial with only odd powers in $T$. 
TABLE 1. Measured molar heat capacity of $\operatorname{IrO}_{2}\left(R=8.3144 \mathrm{~J} \cdot \mathrm{K}^{-1} \cdot \mathrm{mol}^{1}{ }^{1}\right)$

\begin{tabular}{|c|c|c|c|c|c|c|c|c|c|c|c|}
\hline$T \mathbf{K}$ & $C_{p, m} / R$ & $T / \mathbf{K}$ & $C_{p, \mathrm{~m}} / R$ & $T / \mathrm{K}$ & $C_{p, m} R$ & $T / \mathrm{K}$ & $C_{p, \mathbf{m}} / R$ & $T: \mathbf{K}$ & $C_{p, \mathrm{~m}} / R$ & $T: \mathbf{K}$ & $C_{p, m}: R$ \\
\hline \multicolumn{2}{|c|}{ Series 1} & 77.39 & 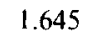 & 179.5 & 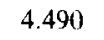 & & & & .0223 & & .2317 \\
\hline 62.48 & 1387 & 84.63 & & & & & & & & & \\
\hline 66.6 & & & & & & & & & & & \\
\hline 72. & & & & & & & & & & & \\
\hline 80.02 & & & & & & & & & & & \\
\hline & & & & & & & & & & & \\
\hline & & & & & & & & & & & \\
\hline 06.96 & 2.572 & & 5 & 242 & 5.7 & 345.71 & 7.275 & & 06 & & 726 \\
\hline \multicolumn{2}{|c|}{ Series II } & 14 & 3.621 & 251.14 & 5.953 & Series & III & 22.29 & 989 & 63.09 & 1.1545 \\
\hline 60.06 & 1.0572 & 153.32 & 3.866 & 260.78 & 6.116 & 6.13 & 0.0057 & 24.25 & 0.1209 & 68.57 & 1.3418 \\
\hline 65.25 & 1.2341 & 162.39 & 4.092 & 268.59 & 6.2 & 8.13 & 0.0107 & & 0.1515 & & \\
\hline 70.62 & 1.4165 & 171.13 & 4.300 & 277.56 & 6.387 & 9.67 & 0.0150 & 28.77 & 0.1890 & & \\
\hline
\end{tabular}

The thermodynamic functions in table 2 were calculated through integration of the fitted polynomial, excluding nuclear-spin and isotope-mixing contributions. and are thus practicable for use in thermochemical calculations.

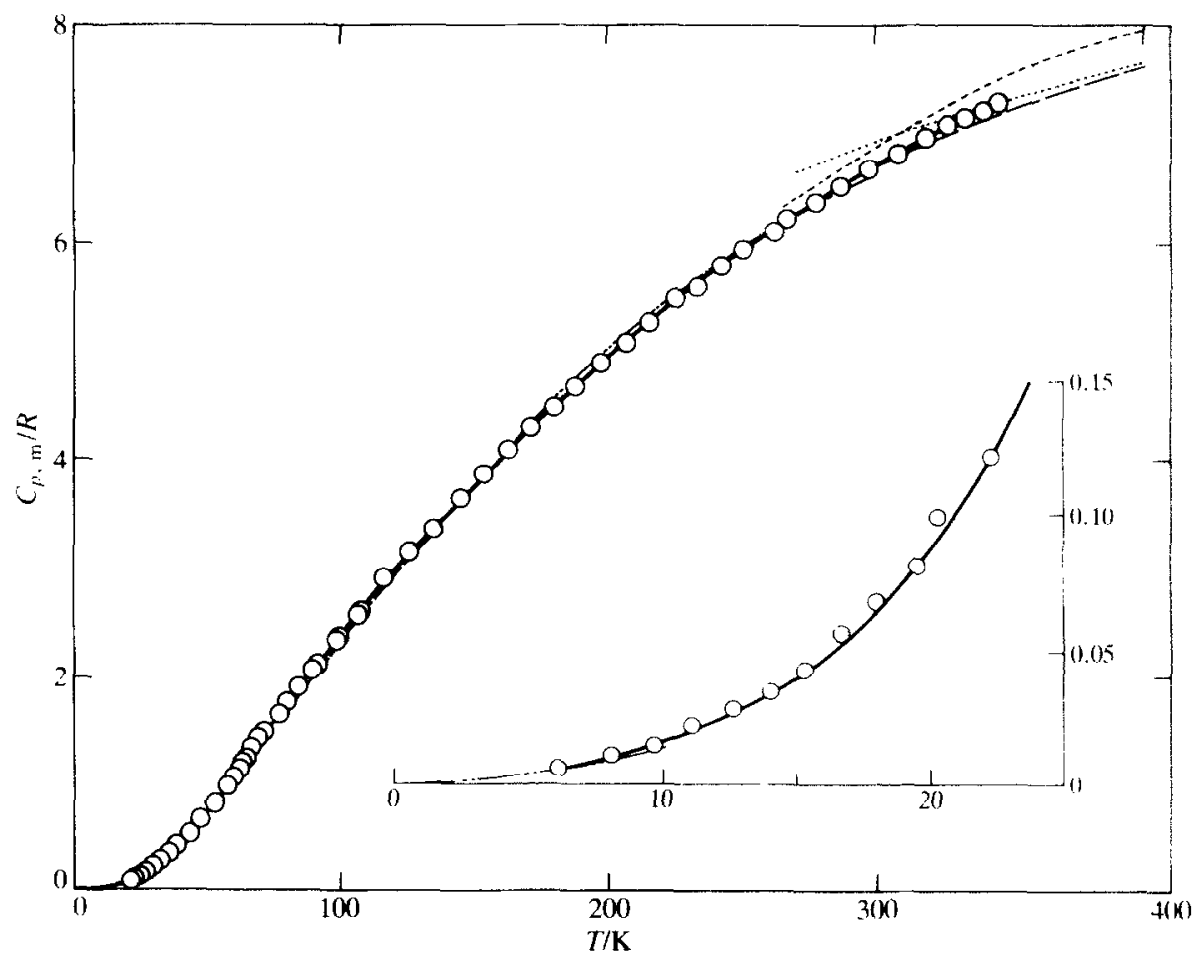

FIGURE 1. The molar heat capacity of $\mathrm{IrO}_{2}$ over the range 0 to $400 \mathrm{~K}:-\mathrm{O}-$, this research:

Passenheim and McCollum;(1) .... Wöhler and Jochum; $;^{(2)} \ldots \ldots$. Cordfunke: ${ }^{(3)} \ldots$. the estimates of Bell et al ${ }^{(7)}$ The molar heat capacity of isostructural $\mathrm{TiO}_{2}$ (rutile) of Shomate ${ }^{(8)}(50$ to $300 \mathrm{~K}$ ) is also, shown: $-\cdots$. 
TABLE 2. Thermodynamic properties of $\operatorname{IrO}_{2}\left(R=8.3144 \mathrm{~J} \cdot \mathrm{K}^{\prime} \cdot \mathrm{mol}{ }^{\prime}\right)$

\begin{tabular}{|c|c|c|c|c|c|c|c|c|c|}
\hline$\underline{T}$ & $C_{r . \mathrm{m}}$ & $\Delta_{0}^{r} S_{\mathrm{m}}$ & $\Delta_{0}^{r} H_{\mathrm{r}}$ & $\Phi_{\mathrm{m}}(T, 0)$ & $T$ & $C_{n, m}$ & $\Delta_{0}^{\mathrm{T}} S_{\mathrm{m}}$ & $\Delta_{0}^{r} H_{\mathrm{m}}$ & $\Phi_{\mathrm{m}}(T, 0)$ \\
\hline$\overline{\mathrm{K}}$ & $R$ & $\bar{R}$ & $R \cdot \mathrm{K}$ & $R$ & $\mathrm{~K}$ & $R$ & $R$ & $R \cdot \overrightarrow{\mathbf{K}}$ & $R$ \\
\hline 5 & 0.005 & 0.004 & 0.010 & 0.0018 & 140 & 3.516 & 2.30 & 207.0 & 0.8266 \\
\hline 10 & 0.016 & 0.010 & 0.058 & 0.0041 & 160 & 4.034 & 2.809 & 282.6 & 1.0429 \\
\hline 15 & 0.039 & 0.021 & 0.197 & 0.0077 & 180 & 4.506 & 3.312 & 368.1 & 1.2672 \\
\hline 20 & 0.076 & 0.039 & 0,479 & 0.0126 & 200 & 4.941 & 3.810 & 462.6 & 1.4966 \\
\hline 25 & 0.133 & 0.061 & 0.992 & 0.0195 & 220 & 5.354 & 4.300 & 565.6 & 1.729 \\
\hline 30 & 0.212 & 0.090 & 1.843 & 0.0285 & 240 & 5.746 & 4.785 & 676.6 & 1.964 \\
\hline 40 & 0.435 & 0.179 & 5.005 & 0.0538 & 260 & 6.105 & 5.257 & 795.2 & 2.199 \\
\hline 50 & 0.725 & 0.307 & 10.758 & 0.0914 & 280 & 6.423 & 5.721 & 920.5 & 2.434 \\
\hline 60 & 1.052 & 0.467 & 19.62 & 0.1403 & 300 & 6.713 & 6.175 & 1051.9 & 2.668 \\
\hline 70 & 1.392 & 0.655 & 31.84 & 0.2001 & 320 & 6.992 & 6.210 & 1188.8 & 2.901 \\
\hline 80 & 1.738 & 0.864 & 47.50 & 0.2698 & 350 & 7.278 & 7.256 & 1403.2 & 3.247 \\
\hline 90 & 2.067 & 1.087 & 66.54 & 0.3481 & & & & & \\
\hline 100 & 2.378 & 1.321 & 88.77 & 0.4336 & 273.15 & 6.318 & 5.564 & 876.9 & 2.353 \\
\hline 120 & 2.961 & 1.80 & 142.22 & 0.6218 & 298.15 & 6.687 & 6.133 & 1039.5 & 2.647 \\
\hline
\end{tabular}

\section{Discussion}

Electric-resistivity measurements made on this compound indicated that electron-phonon and electron-electron interband scattering mechanisms account for the observed temperature dependence. ${ }^{(10.11)}$ The results are consistent with a single d-type band. The product $\chi V_{\mathrm{m}}$ of the paramagnetic susceptibility and the molar volume, and the electronic heat-capacity coefficient $\dot{\gamma}$, are believed to be due mainly to this narrow band. The most important term in $\chi V_{\mathrm{m}}$ is the Pauli contribution which for a non-interacting electron gas is related to the coefficient $;$ by the relation:

$$
\chi V_{\mathrm{m}}^{\prime}=3 \gamma \mu_{\mathrm{B}}^{2} \mu_{0} / \pi^{2} k^{2}
$$

where $\mu_{\mathrm{B}}$ is the Bohr magneton, $k$ is the Boltzmann constant, and $\mu_{0}$ is the permeability of vacuum. The value given by Ryden and Lawson ${ }^{(12)}$ for $\chi V_{\mathrm{m}}$ is $(2.95 \pm 0.06) \times 10^{-9} \mathrm{~m}^{3} \cdot \mathrm{mol}^{-1}$ which is about three times higher than our calorimetric estimation $\left(\chi V_{\mathrm{m}}=0.97 \times 10^{-9} \mathrm{~m}^{3} \cdot \mathrm{mol}^{-1}\right)$. This discrepancy has been interpreted as an enhancement factor in $\chi V_{\mathrm{m}}$ due to the exchange interaction of the electrons in the gas. ${ }^{121}$

Our value $\left\{\gamma /\left(R \cdot \mathrm{K}^{-1}\right)=6.7 \times 10^{-4}\right\}$ agrees with the calorimetric value reported by Passenheim and McCollum ${ }^{(1)}\left\{\gamma /\left(R \cdot \mathrm{K}^{-1}\right)=6.6 \times 10^{-4}\right\}$, although our Debye temperature $\left(\Theta_{\mathrm{D}}=430 \mathrm{~K}\right)$ estimated below $15 \mathrm{~K}$ from the $T^{3}$ term in our fitting equated to $3\left(12 R \pi^{4} / 5\right)\left(T / \Theta_{\mathrm{D}}\right)^{3}$ is lower than theirs. $\Theta_{\mathrm{D}}$ increases steadily up to $200 \mathrm{~K}$ and then remains practically constant up to the highest temperature: $\Theta_{\mathrm{D}}=770 \mathrm{~K}$ or $790 \mathrm{~K}$ if we correct the electronic contribution to the heat capacity assuming a constant $\gamma$ ' value over the whole range of temperatures and neglect the adjustment from $C_{p}$ to $C_{r}$. These values are in considerably better agreement with the values obtained from resistivity $\rho$ measurements at high temperatures $\left\{\Theta_{\mathbf{D}}=(700 \pm 100) \mathrm{K}\right\}$ than the previous comparisons made over different temperature regions for $C_{p}$ and $p$. 
The values estimated by enthalpy differences from the old measurements from Wöhler and Jochum ${ }^{(2)}$ (adjusted to the correct atomic number) fit with our results only over the limited overlap with our highest temperatures (330 to $350 \mathrm{~K})$ and do so somewhat better than the estimates of Bell et al. ${ }^{(7)}$ based on seven other $\mathrm{MO}_{2}$-type solids $\left(\mathrm{M}=\right.$ metal). $\left(\right.$ Cordfunke $^{(3)}$ reports the contrary to be true at higher temperatures.) Moreover, the linear dependence of $C_{p, \mathrm{~m}}$ against $T$ that they reported has been found to be excessive by Cordfunke with new high-temperature enthalpy increments measured over the range 400 to $900 \mathrm{~K}$ with respect to $300 \mathrm{~K}$. Cordfunke's values measured on a portion of the same sample agree well with the present values. The determinations of Passenheim and McCollum $^{(1)}$ below $10 \mathrm{~K}$ yield a similar value of $\gamma$ (as already noted) but are about 15 per cent below our values at $10 \mathrm{~K}$. This discrepancy (compare figure 1) is outside their estimated 5 per cent uncertainty limit. They observed the tail of a nuclear-spin ordering transition below $1 \mathrm{~K}$.

Although the cationic mass of titanium is about 0.25 that of Ir, the molecular volumes are $0.03200 \mathrm{~nm}^{3}$ for $\mathrm{IrO}_{2}$ and $0.03122 \mathrm{~nm}^{3}$ for isostructural $\mathrm{TiO}_{2}$ (rutile): the $298.15 \mathrm{~K}$ molar entropies of $\mathrm{IrO}_{2}$ and $\mathrm{TiO}_{2}(6.133 R$ and $6.004 R)$ are nearly identical. This is consistent with volumetric dependence advanced by Chirico and Westrum, ${ }^{(13)}$ and by Westrum, ${ }^{(14-16)}$ over the entropy-producing temperature region, and is in contrast with that of Latimer's scheme ${ }^{(17)}$ based on cationic masses.

We appreciate the cooperation of W. A. Plautz in the computer evaluation of the thermodynamics of this substance.

\section{REFERENCES}

1. Passenheim, B. C.; McCollum, D. C. J. Chem. Phys. 1969, 51, 320.

2. Wöhler, L.; Jochum, N. Z. Phys. Chem. 1933, 167 A. 169.

Cordfunke. E. H. P. Thermochimica Acta 1981, 50, 177.

4 Westrum, E. F., Jr.: McCullough, J. P. Experimenal Thermodynamics, Vol. I. Scott, D W.: McCullough, J. P.: editors. Butterworths: London. 1968.

5 Stimson, H. F. J. Res. Natl. Bur. Stands. 1961, 65A. 139.

6 McCrackin, F. L.: Chang. S.-S. Rev. Sci. Instrum. 1975, 46. 550.

7. Bell, W. E.; Tagami, M.; Inyard, R. F. J. Phys. Chem. 1966, 70, 2048.

8 Shomate, C. H.J. Am. Chem. Soc. 1947, 69, 2 I8.

y Justice, B. H. Thermal Data Fitting with Orthogonal Functions and Combined Table Generation. The FITAB Program. Ann Arbor, Mi. 1969.

10) Ryden. W. D.: Lawson. A. W.; Sartain, C. C. Phus. Rev R 1970. 1. 1494

11. Butler, S. R.; Gillson. J. L. Mat. Res. Bull. 1971, 6, 81 .

12 Ryden, W. D.: Lawson, A. W. J. Chem. Phys. 1970, 52. 6058.

13 Chirico, R. D.: Westrum, E. F.. Jr. J. Chem. Thermodinamics 1980, 12. 71: 1980. 12, 311: 1981, 13. 519.

14 Westrum. E. F., Jr. Proceedings of the 6th International Conference on Thermodinamics at Mersehurg, G.D.R. 1980. Leipzig. 1981, p. 1.

15. Westrum. E. F., Jr. Netsusokutei 1981, 8, 106.

16. Westrum. E. F., Jr. J. Chem. Thermodynamics 1983, 15, 305.

17 latimer. W. M. J. Am. Chem. Soc. 1921, 43, 818; ihid. 1951, 73. 1480. 